\title{
Impact of a history of metastases or synchronous metastases on survival in patients with locally recurrent rectal cancer
}

Citation for published version (APA):

Voogt, E. L. K., van Zoggel, D. M. G. I., Kusters, M., Nieuwenhuijzen, G. A. P., Cnossen, J. S., Creemers, G. J., van Lijnschoten, G., Nederend, J., Roef, M. J., Burger, J. W. A., \& Rutten, H. J. T. (2021). Impact of a history of metastases or synchronous metastases on survival in patients with locally recurrent rectal cancer. Colorectal Disease, 23(5), 1120-1131. https://doi.org/10.1111/codi.15537

Document status and date:

Published: 01/05/2021

DOI:

10.1111/codi. 15537

Document Version:

Publisher's PDF, also known as Version of record

Document license:

Taverne

Please check the document version of this publication:

- A submitted manuscript is the version of the article upon submission and before peer-review. There can be important differences between the submitted version and the official published version of record.

People interested in the research are advised to contact the author for the final version of the publication, or visit the DOI to the publisher's website.

- The final author version and the galley proof are versions of the publication after peer review.

- The final published version features the final layout of the paper including the volume, issue and page numbers.

Link to publication

\footnotetext{
General rights rights.

- You may freely distribute the URL identifying the publication in the public portal. please follow below link for the End User Agreement:

www.umlib.nl/taverne-license

Take down policy

If you believe that this document breaches copyright please contact us at:

repository@maastrichtuniversity.nl

providing details and we will investigate your claim.
}

Copyright and moral rights for the publications made accessible in the public portal are retained by the authors and/or other copyright owners and it is a condition of accessing publications that users recognise and abide by the legal requirements associated with these

- Users may download and print one copy of any publication from the public portal for the purpose of private study or research.

- You may not further distribute the material or use it for any profit-making activity or commercial gain

If the publication is distributed under the terms of Article $25 \mathrm{fa}$ of the Dutch Copyright Act, indicated by the "Taverne" license above, 


\title{
Impact of a history of metastases or synchronous metastases on survival in patients with locally recurrent rectal cancer
}

\author{
E. L. K. Voogt ${ }^{1}$ | D. M. G. I. van Zoggel ${ }^{1}$ | M. Kusters ${ }^{2}$ | G. A. P. Nieuwenhuijzen ${ }^{1}$ |

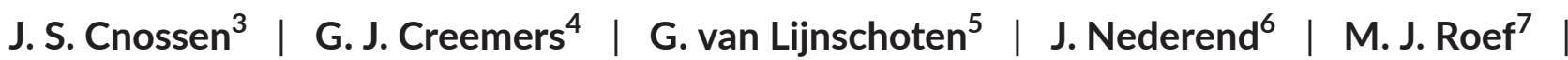 \\ \begin{tabular}{l|l} 
J. W. A. Burger & H. J. T. Rutten \\
& 1,8
\end{tabular}
}

${ }^{1}$ Department of Surgery, Catharina Hospital, Eindhoven, The Netherlands

${ }^{2}$ Department of Surgery, Amsterdam University Medical Centres, Location VUmc, Amsterdam, The Netherlands

${ }^{3}$ Department of Radiation Oncology, Catharina Hospital, Eindhoven, The Netherlands

${ }^{4}$ Department of Medical Oncology, Catharina Hospital Eindhoven, Eindhoven, The Netherlands

${ }^{5}$ Pathology Department, PAMM Laboratory for Pathology and Medical Microbiology, Eindhoven, The Netherlands

${ }^{6}$ Department of Radiology, Catharina Hospital, Eindhoven, The Netherlands

${ }^{7}$ Department of Nuclear Medicine, Catharina Hospital, Eindhoven, The Netherlands

${ }^{8}$ GROW School for Oncology and Developmental Biology, Maastricht University, Maastricht, The Netherlands

Correspondence

Eva L. K. Voogt, Department of Surgery, Catharina Ziekenhuis Eindhoven, Michelangelolaan 2, 5623 EJ Eindhoven, The Netherlands.

Email: eva.voogt@catharinaziekenhuis.nl

Funding information

This research did not receive any specific grant from funding agencies in the public, commercial or not-for-profit sectors.

\begin{abstract}
Aim: Patients with locally recurrent rectal cancer (LRRC) frequently present with either synchronous metastases or a history of metastases. This study was conducted to evaluate whether LRRC patients without metastases have a different oncological outcome compared to patients with a history of metastases treated with curative intent or patients with potentially curable synchronous metastases.

Method: All consecutive LRRC patients who underwent intentionally curative surgery between 2005 and 2017 in a large tertiary hospital were retrospectively reviewed and categorized as having no metastases, a history of (curatively treated) metastases or synchronous metastases. Patients with unresectable distant metastases were excluded from the analysis.

Results: Of the 349 patients who were analysed, 261 (75\%) had no metastases, 42 (12\%) had a history of metastases and $46(13 \%)$ had synchronous metastases. The 3-year metastasis-free survival was $52 \%, 33 \%$ and $13 \%$ in patients without metastases, with a history of metastases, and with synchronous metastases, respectively $(P<0.001)$ A history of metastases did not influence overall survival (OS), but there was a trend towards a worse OS in patients with synchronous metastases compared with patients without synchronous metastases (hazard ratio 1.43; 95\% $\mathrm{Cl} 0.98-2.11$ ).

Conclusion: LRRC patients with a history of curatively treated metastases have an OS comparable to that in patients without metastases and should therefore be treated with curative intent. However, LRRC patients with synchronous metastases have a poor metastasis-free survival and worse OS; in these patients, an individualized treatment approach to observe the behaviour of the disease is recommended.
\end{abstract}

KEYWORDS

distant metastases, locally recurrent rectal cancer, metastasis-free survival, overall survival, prognosis

Voogt and van Zoggel contributed equally to this manuscript. 


\section{INTRODUCTION}

The European Society for Medical Oncology guidelines for the management of patients with metastatic (colo-)rectal cancer specify treatment strategies based on the possibility of achieving a resection with clear resection margins (RO resection) of the primary tumour and an $\mathrm{RO}$ resection or ablation of the solitary or oligometastatic disease [1]. In marginally resectable metastatic lesions, induction chemotherapy may enable conversion of these lesions to a resectable or ablatable state [1]. This concept has led to the development of treatment strategies comprising a combination of neoadjuvant (chemo)radiotherapy and systemic treatment in patients with metastatic primary rectal cancer, resulting in long-term survival rates exceeding $50 \%[2,3]$.

Similarly, the treatment of locally recurrent rectal cancer (LRRC) is intended to achieve an $\mathrm{RO}$ resection-the most important prognostic factor for survival. Depending on local protocols, treatment may comprise neoadjuvant chemo(re)irradiation and extensive surgery with/without intra-operative radiotherapy [4-7]. Induction chemotherapy is currently being evaluated as a promising addition to this treatment to improve resectability and oncological outcomes [8,9].

Synchronous systemic disease is a major problem in LRRC, as approximately $50 \%$ of patients present with distant metastases [10]. In particular, patients who develop LRRC within 1 year after the primary resection or those treated with neoadjuvant radiotherapy for the primary tumour are prone to early development of metastatic disease [10].

As metastatic disease is considered an indicator of aggressive tumour biology, treatment options for LRRC patients with synchronous metastases or a history of metastases (m-LRRC) are usually limited to palliative intent, thereby resulting in poor survival rates [11-14]. However, it is unclear whether these metastases progress rapidly or whether treatment with curative intent might be feasible in some patients.

In our centre, the treatment principles for metastatic primary rectal cancer are applied in patients with $\mathrm{m}$-LRRC. Metastatic disease is considered to be cured if patients with a history of metastases have no signs of recurrent metastatic disease. Synchronous metastases are considered curable if an $\mathrm{RO}$ resection of the LRRC and radical treatment of the metastases can be achieved.

This study aimed to comparatively evaluate oncological outcomes in LRRC patients without metastases, those with a history of metastases and those with synchronous metastases.

\section{METHODS}

\section{Patients}

The data of consecutive LRRC patients treated at the Catharina Hospital (CZE), a national tertiary referral centre for LRRC, were prospectively collected in a database and retrospectively reviewed. This study selected all LRRC patients who underwent a curative
What does this paper add to the existing literature?

Many patients with locally recurrent rectal cancer (LRRC) present with synchronous metastases or a history of metastases. This is the largest study to date comparing the oncological outcomes in LRRC patients without distant metastases to those with a history of metastases or with synchronous metastases.

resection between January 2005 and December 2017. Patients with local unresectable disease or untreatable distant metastases and patients with progressive disease during neoadjuvant treatment who did not undergo a resection were excluded.

Selected patients were categorized as follows: without metastases (no metastases); with curatively treated synchronous or metachronous metastases with the primary tumour (history of metastases); and with resectable metastases diagnosed simultaneously with the LRRC, during neoadjuvant treatment or perioperatively (synchronous metastases). Patients with both a history of metastases and synchronous metastases were categorized as having 'synchronous metastases'.

This study was approved by the local medical ethics board (Medical Research Ethics Committees United-Nieuwegein, registration number W19.031).

\section{Treatment local recurrence}

The optimal treatment strategy and timing for all patients were determined at a multidisciplinary team (MDT) meeting attended by a specialized surgical oncologist, medical oncologist, radiation oncologist, radiologist, nuclear medicine specialist and pathologist. Patients were eligible for curative treatment if an $\mathrm{RO}$ resection of the LRRC and curative treatment of metastatic disease were achievable.

Curative treatment generally comprised neoadjuvant chemoradiotherapy with concomitant capecitabine administered twice daily. Radiotherapy dose was 50-50.4 Gy, delivered in 25-28 fractions of 1.8-2.0 Gy. In the case of previous radiotherapy, the dose was 30-30.6 Gy, delivered in 15-17 fractions of 1.8-2.0 Gy. The gross tumour volume was expanded with a margin of at least $1 \mathrm{~cm}$ for the clinical target volume. The planning target volume consisted of the clinical target volume plus a $2 \mathrm{~cm}$ margin.

Since 2010, induction chemotherapy before chemo(re)irradiation has been introduced as a treatment option to improve local downstaging and, thereby, resectability.

The surgical approach depended on the location and extent of the LRRC and was performed by experienced surgical oncologists. For the purpose of this study, we categorized the type of resection as low anterior resection, abdominoperineal resection, multivisceral resection or nonvisceral resection. A multivisceral resection was defined as a resection including a resection of the rectum and 
TABLE 1 Baseline and primary tumour characteristics

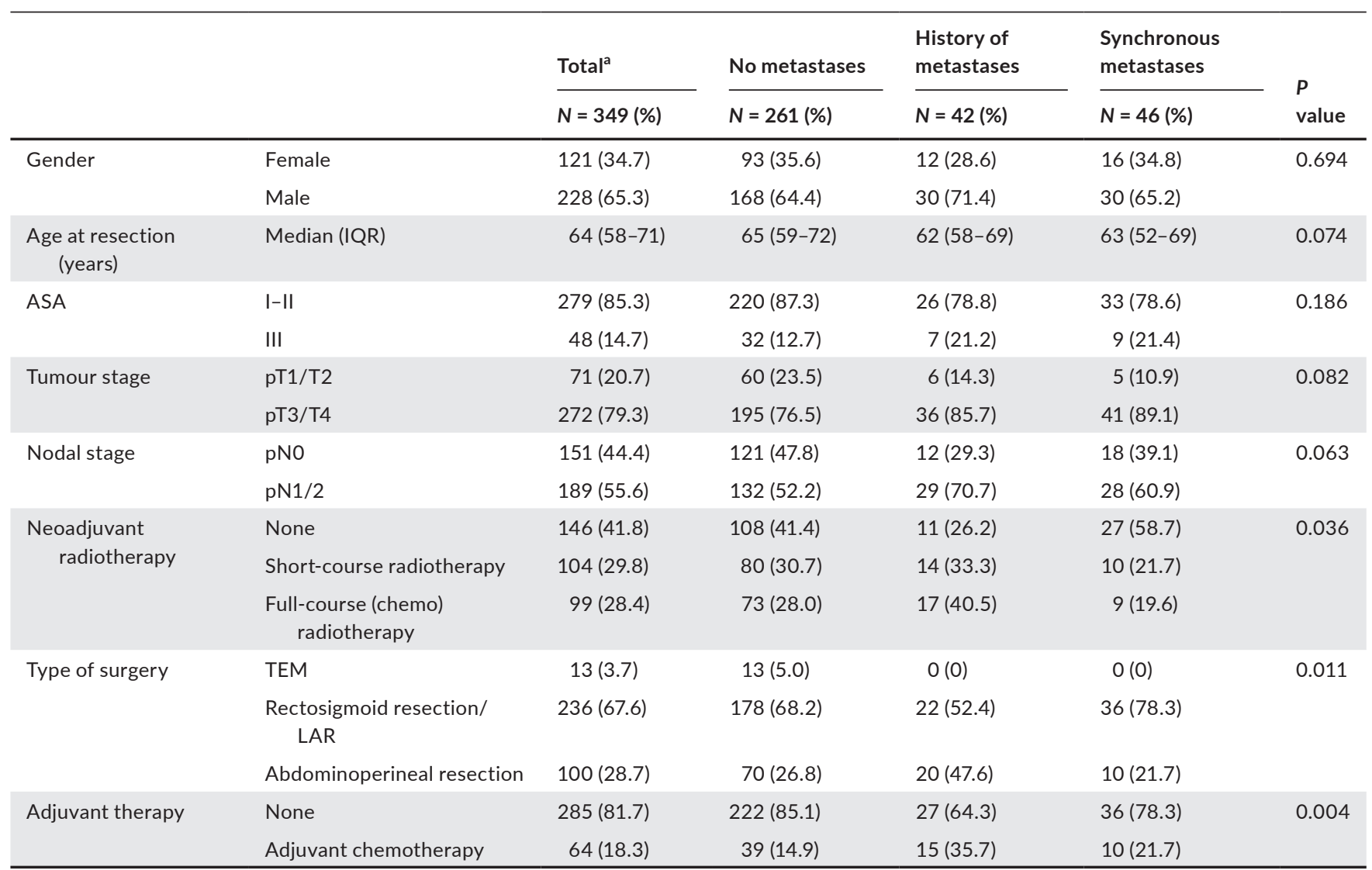

Abbreviations: ASA, American Society of Anesthesiologists Physical Status; IQR, interquartile range; LAR, low anterior resection; TEM, transanal endoscopic microsurgery.

${ }^{a}$ Numbers do not always add up to 349 due to missing values (ASA $n=22$; tumour stage $n=6$; nodal stage $n=9$ ).

at least one pelvic organ/structure (i.e., bladder, prostate, vesicles, uterus, vagina, ovaries, sacrum). A nonvisceral resection was defined as a resection of the recurrence without a resection of the rectum.

In the case of involved or narrow resection margins and when deemed feasible, intraoperative radiotherapy (IORT; dose 10$12.5 \mathrm{~Gy}$ ) was administered. IORT was delivered by electron beam radiotherapy. In earlier years this was delivered using an Elekta SL-25 linear accelerator (Elekta Oncology Systems, Stockholm, Sweden). From 2016 onwards, IORT was delivered using a Mobetron 2000 linear accelerator (IntraOp Inc., Sunnyvale CA, USA).

\section{Treatment distant metastases}

The treatment strategy for synchronous metastases was determined in an MDT meeting. Liver metastases were treated with surgery, radiofrequency ablation or stereotactic radiotherapy, all performed in the referring or a partnering hospital. Lung metastases were treated with metastasectomy or stereotactic radiotherapy. Lung and liver metastases were treated either during the interval between neoadjuvant (chemo)radiotherapy and surgery or postoperatively. In the case of peritoneal metastases, cytoreductive surgery (CRS) and hyperthermic intraperitoneal chemotherapy (HIPEC) was performed simultaneously with the LRRC resection. Inguinal or para-aortic lymph node metastases were treated with a lymphadenectomy simultaneous with the LRRC resection if residual disease was suspected after neoadjuvant treatment.

\section{Follow-up}

Patients were followed up in the CZE or in the referring hospital, according to the patient's preference. Follow-up was performed according to the Dutch guidelines for colorectal cancer and consisted of carcinoembryonic antigen measurements four times a year during the first 2 years and twice a year during years $3-5$. Ultrasonography of the liver and chest radiography or a thoracoabdominal computed tomography scan was performed twice a year during the first 2 years and once a year thereafter.

\section{End-points and statistical analysis}

Continuous data were reported as median (interquartile range), and categorical data as count (percentage). To compare individual 
TABLE 2 Recurrent tumour characteristics, treatment and outcomes

\begin{tabular}{|c|c|c|c|c|c|c|}
\hline & & Total & No metastases & $\begin{array}{l}\text { History of } \\
\text { metastases }\end{array}$ & $\begin{array}{l}\text { Synchronous } \\
\text { metastases }\end{array}$ & \\
\hline & & $N=349(\%)$ & $N=261(\%)$ & $N=42(\%)$ & $N=46(\%)$ & value \\
\hline Time to recurrence (months) ${ }^{a}$ & Median (IQR) & $31(19-50)$ & $31(19-49)$ & $42(34-63)$ & $26(17-47)$ & 0.013 \\
\hline \multirow[t]{2}{*}{ Number of recurrences } & 1 & $296(84.8)$ & $229(87.7)$ & $30(71.4)$ & $37(80.4)$ & 0.016 \\
\hline & $2-3$ & $53(15.2)$ & $32(12.3)$ & $12(28.6)$ & $9(19.6)$ & \\
\hline Multifocality & Yes & 39 (11.2) & $26(10.0)$ & $6(14.3)$ & $7(15.2)$ & \\
\hline \multirow[t]{2}{*}{ Induction chemotherapy } & No & $237(67.9)$ & $186(71.3)$ & $27(64.3)$ & $24(52.2)$ & 0.033 \\
\hline & Yes & $112(32.1)$ & $75(28.7)$ & $15(35.7)$ & $22(47.8)$ & \\
\hline \multirow[t]{2}{*}{ Neoadjuvant radiotherapy } & None & $27(7.7)$ & $14(5.4)$ & $8(19.0)$ & $5(11.1)$ & 0.012 \\
\hline & (Chemo)reirradiation & $202(57.9)$ & $157(60.2)$ & $25(59.5)$ & $20(43.5)$ & \\
\hline \multirow[t]{4}{*}{ Type of surgery } & Low anterior resection & $54(15.5)$ & $39(14.9)$ & $5(11.9)$ & $10(21.7)$ & 0.744 \\
\hline & $\begin{array}{l}\text { Abdominoperineal } \\
\text { resection }\end{array}$ & $25(7.2)$ & $17(6.5)$ & $4(9.5)$ & $4(8.7)$ & \\
\hline & Nonvisceral resection & $32(9.2)$ & $24(9.2)$ & $5(11.9)$ & $3(6.5)$ & \\
\hline & Multivisceral resection & $238(68.2)$ & $181(69.3)$ & $28(66.7)$ & $29(63.0)$ & \\
\hline \multirow[t]{2}{*}{ Intraoperative radiotherapy } & No & $60(17.2)$ & $43(16.5)$ & 8 (19.0) & 9 (19.6) & 0.828 \\
\hline & Yes & $289(82.8)$ & $218(83.5)$ & $34(81.0)$ & $37(80.4)$ & \\
\hline
\end{tabular}

Abbreviation: IQR, interquartile range.

${ }^{a}$ Duration between primary surgery and current recurrence; missing values $n=8$.

${ }^{b}$ Missing values $n=36$, as these patients had a complete pathological response.

variables, the Mann-Whitney $U$ and chi-squared tests were performed as appropriate.

The end-points were overall survival (OS:time between the date of LRRC surgery and the date of death or last follow-up), local recurrence-free survival (LRFS:time between the date of LRRC surgery and the date of histologically or radiologically proven local re-recurrence or last follow-up), and metastasis-free survival (MFS:time between the date of LRRC surgery and the date of histologically or radiologically proven distant metastases or last follow-up).

The OS, LFRS and MFS were estimated using the Kaplan-Meier method, and differences were assessed using the log rank test. For multivariable analyses, the Cox regression method was applied using all variables with a $P<0.100$ in the univariable analyses. Two-sided $P$ values $<0.05$ were considered statistically significant. Statistical analysis was performed using IBM SPSS ${ }^{\circledR}$ version 23 for Windows ${ }^{\circledR}$ (IBM, Armonk, NY, USA).

\section{RESULTS}

\section{Patients}

Of the 349 patients who met the selection criteria, 261 (75\%) never had distant metastases, 42 (12\%) had a history of metastases and 46 (13\%) had synchronous metastases; $14 / 46$ patients also had a history of metastases. All included patients underwent pelvic surgery as well as treatment for their metastatic disease. Patient characteristics and details of the primary and recurrent tumour are shown in Tables 1 and 2, respectively. Patients with synchronous metastases had a shorter interval between resection of the primary tumour and the LRRC (26 months) than patients without metastases and patients with a history of metastases (31 and 42 months respectively, $P=0.014)$. Patients with synchronous metastases more often received induction chemotherapy for their LRRC than patients without or those with a history of metastases $(P=0.033)$, and the latter more 


\begin{tabular}{|c|c|c|c|}
\hline & \multirow[b]{2}{*}{$\begin{array}{l}\text { History of metastases } \\
(N=42)\end{array}$} & \multicolumn{2}{|c|}{$\begin{array}{l}\text { Synchronous metastases } \\
(N=46)\end{array}$} \\
\hline & & $\begin{array}{l}\text { History of } \\
\text { metastases }\end{array}$ & $\begin{array}{l}\text { Synchronous } \\
\text { metastases }\end{array}$ \\
\hline Liver $^{a}$ & 23 & 9 & 15 \\
\hline Single & 10 & 3 & 9 \\
\hline Multiple & 13 & 6 & 6 \\
\hline \multicolumn{4}{|l|}{ Treatment $\mathrm{t}^{\mathrm{b}, \mathrm{c}}$} \\
\hline $\begin{array}{l}\text { Resection (e.g., } \\
\text { metastasectomy, } \\
\text { hemihepatectomy) }\end{array}$ & 22 & 8 & 11 \\
\hline RFA & 4 & 3 & 1 \\
\hline Stereotactic radiotherapy & 0 & 0 & 2 \\
\hline Systemic chemotherapy & 0 & 0 & 2 \\
\hline Lung $^{a}$ & 13 & 2 & 6 \\
\hline Single & 11 & 1 & 3 \\
\hline Multiple & 2 & 1 & 3 \\
\hline \multicolumn{4}{|l|}{ Treatment } \\
\hline Resection & 11 & 2 & 1 \\
\hline Stereotactic radiotherapy & 2 & 0 & 4 \\
\hline Unknown & 0 & 0 & 1 \\
\hline Peritoneal $^{\mathrm{a}, \mathrm{d}}$ & 7 & 5 & 18 \\
\hline Single $(\mathrm{PCl} \leq 2)$ & 3 & 1 & 6 \\
\hline Multiple $(\mathrm{PCl}>2)$ & 4 & 4 & 12 \\
\hline \multicolumn{4}{|l|}{ Treatment } \\
\hline $\begin{array}{l}\text { Cytoreductive surgery + } \\
\text { HIPEC }\end{array}$ & 3 & 2 & 10 \\
\hline $\begin{array}{l}\text { Cytoreductive surgery } \\
\text { - HIPEC }\end{array}$ & 4 & 3 & 8 \\
\hline $\begin{array}{l}\text { Lymph nodes (inguinal/ } \\
\text { para-aortic) }\end{array}$ & 3 & 1 & 6 \\
\hline Single & 2 & 0 & 2 \\
\hline Multiple & 1 & 1 & 4 \\
\hline \multicolumn{4}{|l|}{ Treatment } \\
\hline Metastasectomy & 3 & 0 & 3 \\
\hline Systemic chemotherapy & 0 & 1 & 3 \\
\hline Other $^{a}$ & 0 & 0 & 2 \\
\hline Single & NA & NA & 2 \\
\hline Multiple & NA & NA & 0 \\
\hline \multicolumn{4}{|l|}{ Treatment } \\
\hline Metastasectomy & NA & 1 & 2 \\
\hline Systemic chemotherapy & NA & 0 & 1 \\
\hline
\end{tabular}

TABLE 3 Location, extent and treatment of metastases

Abbreviations: HIPEC, hyperthermic intraperitoneal chemotherapy; NA, not applicable; PCl, peritoneal cancer index; RFA, radio frequency ablation.

${ }^{a}$ The numbers are not in agreement with the number of patients with metastases as some patients were diagnosed with metastases in more than one organ.

${ }^{b}$ One patient could have undergone multiple treatments in cases of multiple metastases (e.g., metastasectomy and RFA).

${ }^{\mathrm{C}}$ Only the definitive treatment for a specific metastasis is listed. If neoadjuvant chemotherapy was administered before metastasectomy, the chemotherapy was not scored as a treatment.

${ }^{d}$ Including metastases in the ovary and abdominal wall. 
FIGURE 1 Overall survival (a), local recurrence free survival (b) and metastasis-free survival (c) in LRRC patients without metastases, with a history of metastases and with synchronous metastases

\section{(A) Overall survival}

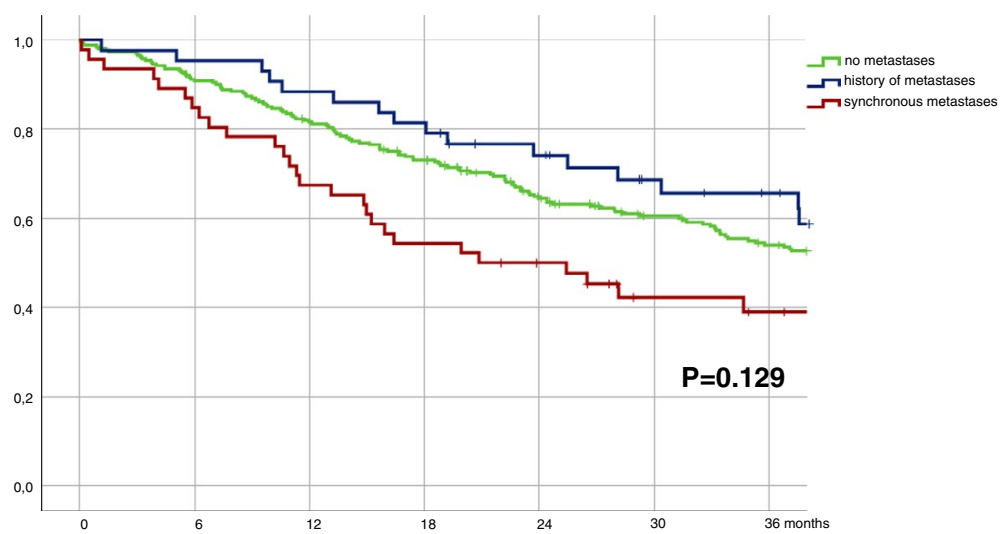

No. at risk No metastases $\quad 261 \quad 237$

History of metastases

Synchronous metastases 46

(B) Local recurrence free survival

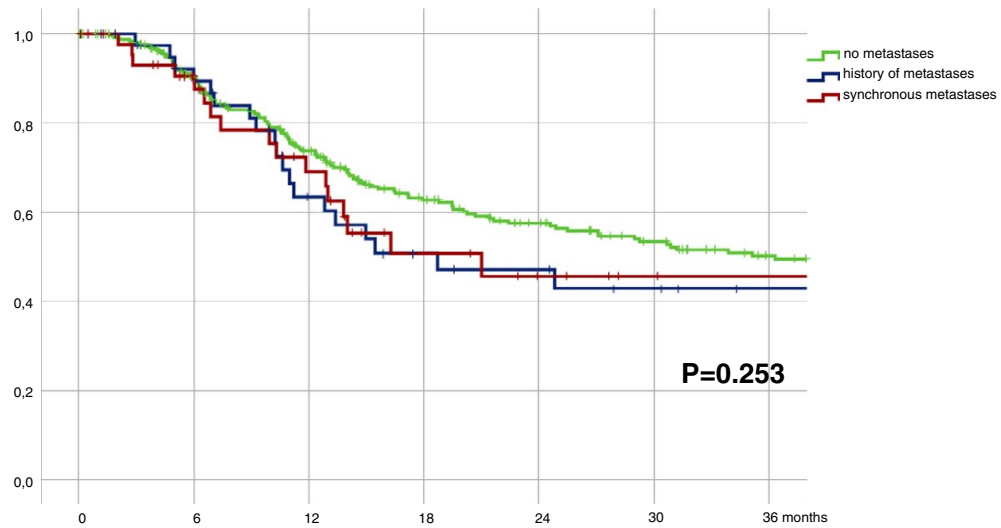

No. at risk

No metastases

$\begin{array}{lll}\text { History of metastases } & 41 & 214\end{array}$

Synchronous metastases $46 \quad 31$

(C) Metastasis free survival

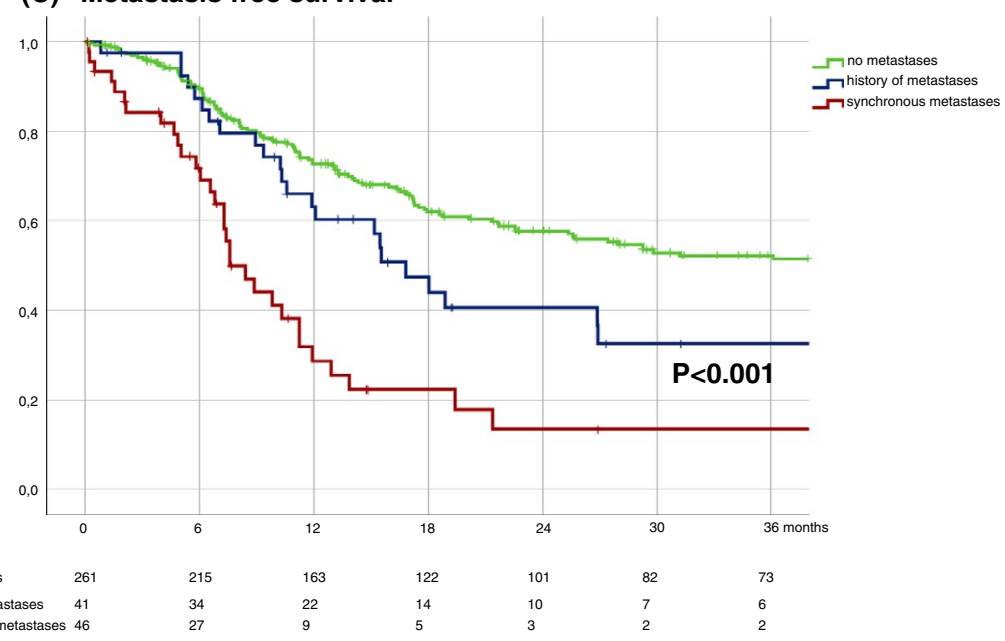

often underwent (chemo)reirradiation for the LRRC than patients with synchronous metastases, who underwent full-course (chemo) radiotherapy more often $(P=0.012)$. Intraoperative radiotherapy was delivered in $82.8 \%$ of the patients. A multivisceral resection was performed in 238 patients; details about the organs resected with this multivisceral resection are show in Table S1.

\section{Location and treatment of metastases}

Details about the types of metastases are shown in Table 3. The majority of the patients with a history of metastases had liver metastases ( $n=23,54 \%$ ), which were mainly treated with metastasectomy ( $n=22)$. Thirteen patients had lung metastases (31\%), mainly treated 
TABLE 4 Results of univariable and multivariable analyses

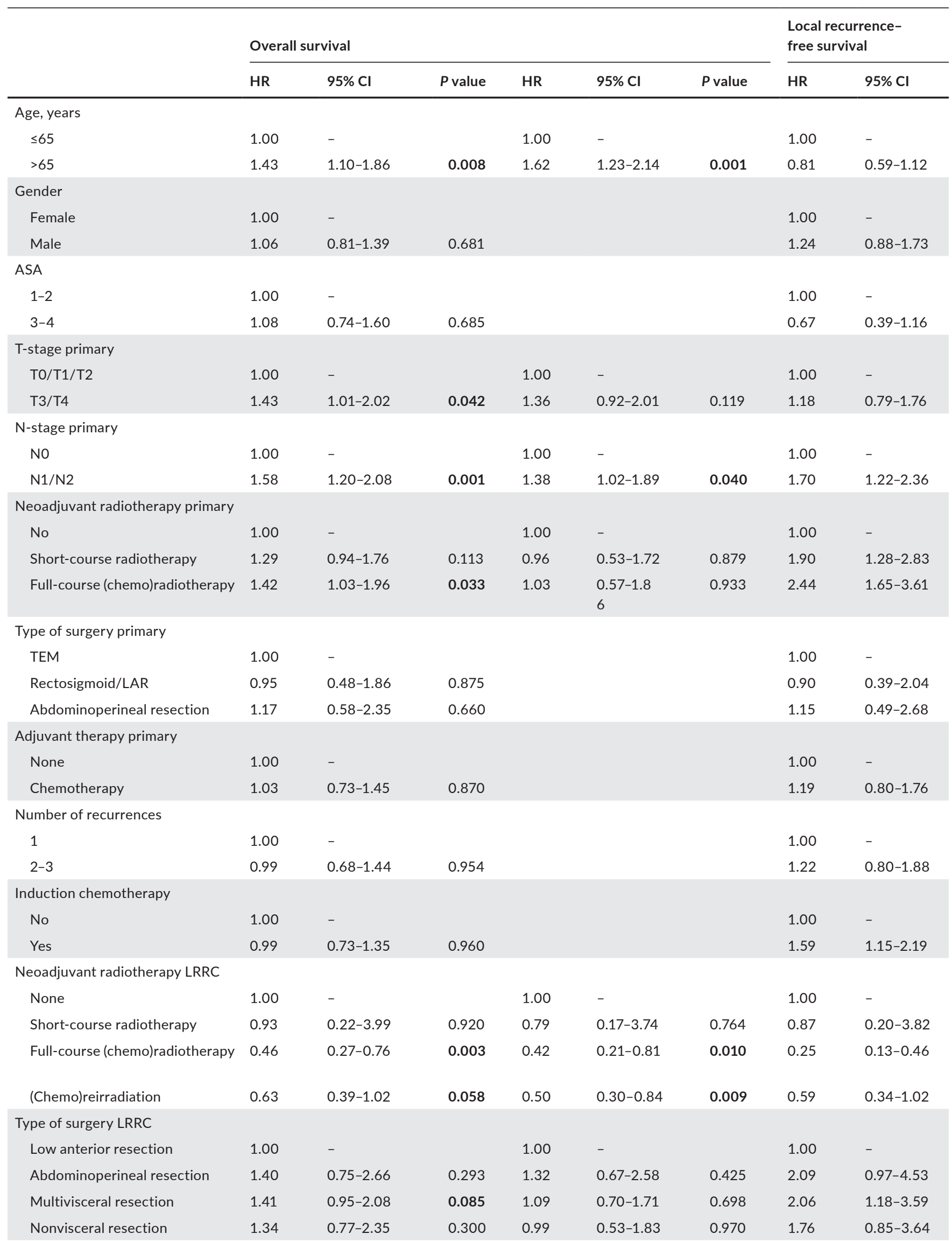


Metastasis-free survival

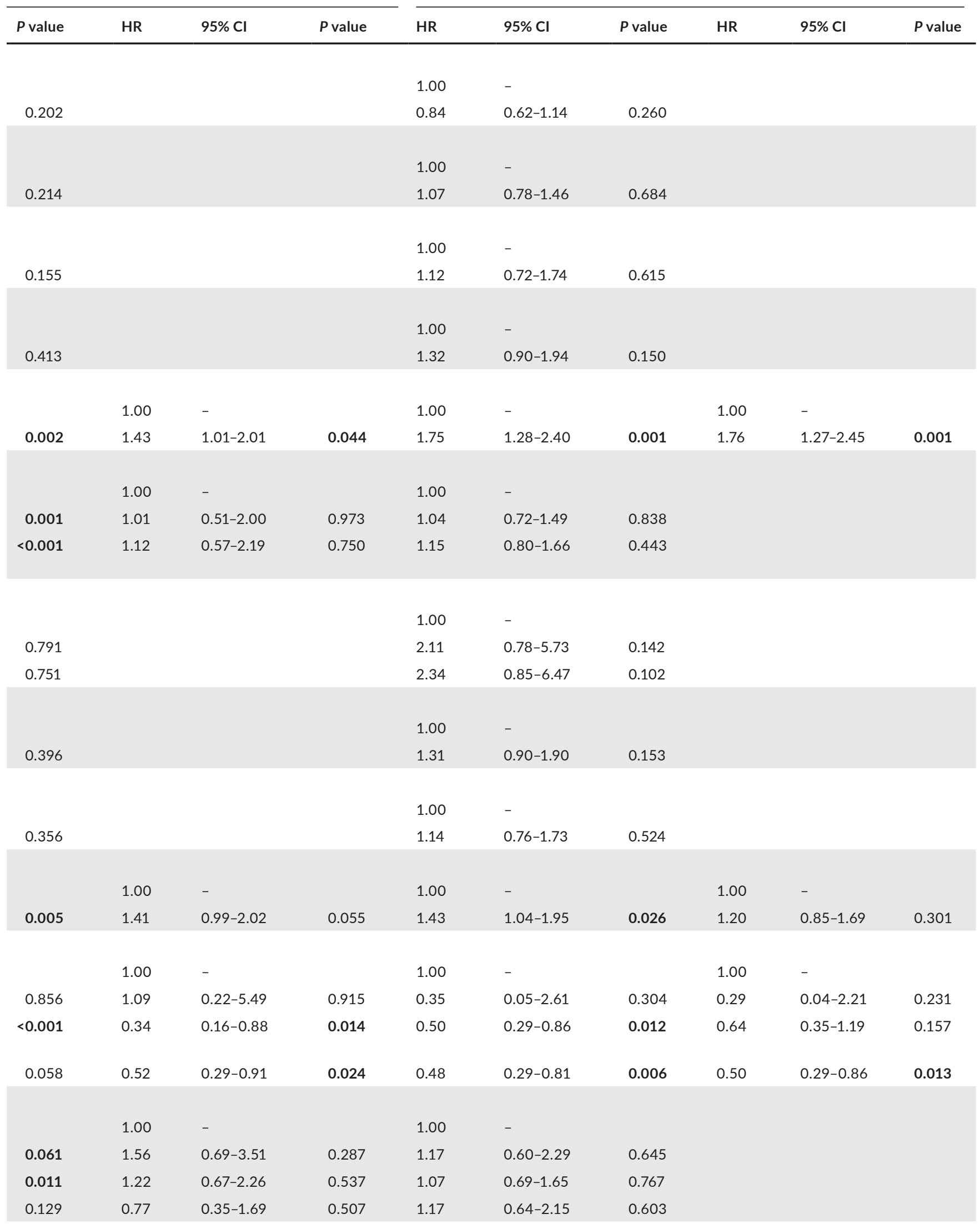




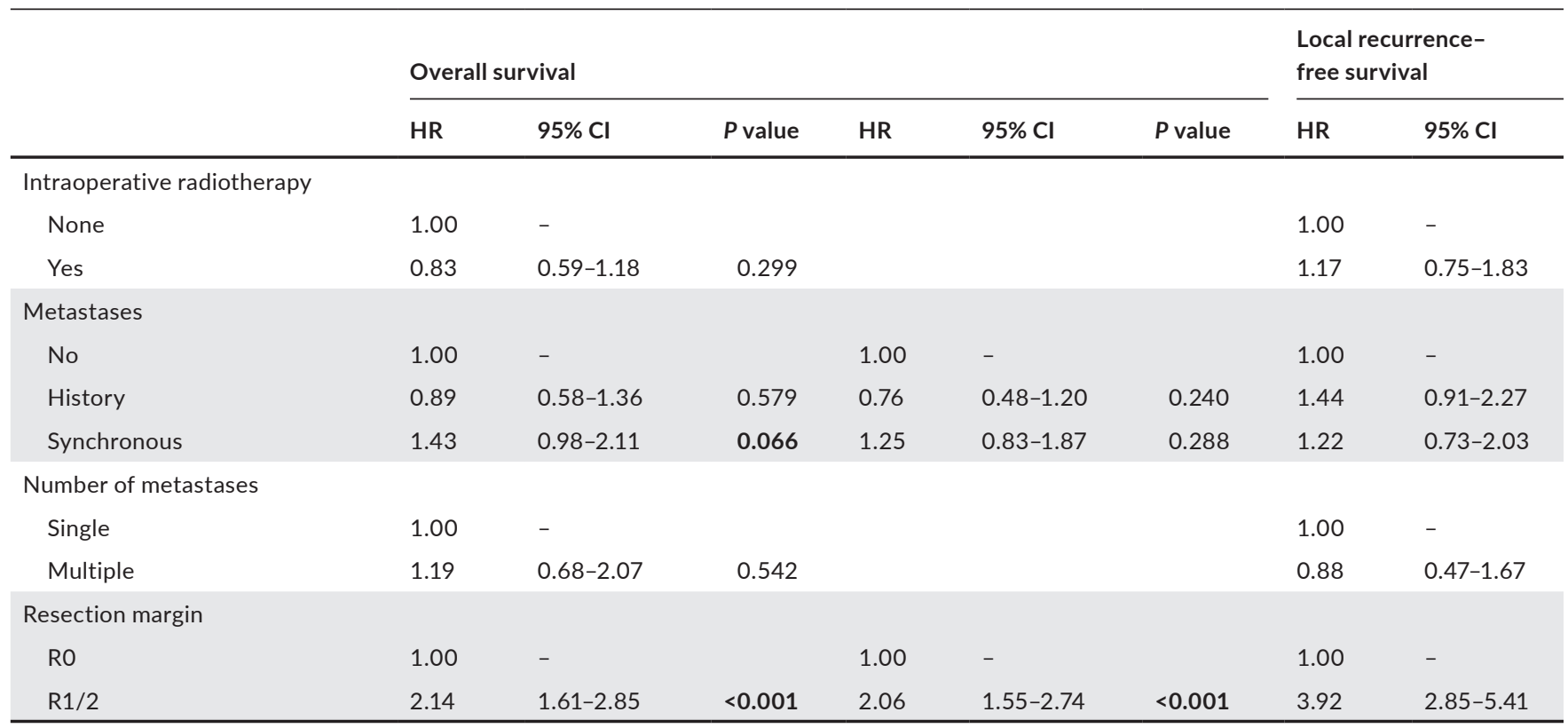

Note: $P$ values in bold indicate a statistically significant difference.

Abbreviations: ASA, American Society of Anesthesiologists Physical Status; HR, hazard ratio; LAR, low anterior resection; LRRC, locally recurrent rectal cancer; TEM, transanal endoscopic microsurgery.

with metastasectomy $(n=11)$. Seven patients $(17 \%)$ had peritoneal metastases that were treated with CRS \pm HIPEC.

Patients with synchronous metastases mostly presented with liver or peritoneal metastases $(n=15$ and $n=18,32 \%$ and 39\%, respectively), which were mainly treated with metastasectomy $(n=11)$ or CRS \pm HIPEC, respectively. Lymph node metastases ( $n=6,13 \%$ ) either disappeared after neoadjuvant treatment $(n=3)$ or required additional lymphadenectomy $(n=3)$.

\section{Overall survival}

The 3-year OS rate in all patients was 53\% (median 39.7 months), and 54\%, 65\%, and 39\% (median 43.0, 40.7, and 20.8 months) in patients without metastases, with a history of metastases, and with synchronous metastases, respectively $(P=0.129$; Figure $1 \mathrm{~A})$. When comparing groups separately, no significant difference in OS was observed in patients without metastases versus those with a history of metastases $(P=0.592)$, without metastases versus synchronous metastases $(P=0.071)$, and a history of metastases versus synchronous metastases $(P=0.091)$. A comparison between patients with synchronous metastases and those without synchronous metastases showed a trend towards a significant difference in the 3-year OS ( $39 \%$ vs. $56 \%$ respectively, $P=0.051$ ).

\section{Local recurrence}

The 3-year LRFS rate in all patients was 49\% (median LRFS 31.2 months), and $51 \%, 40 \%$, and $46 \%$ in patients without metastases, with a history of metastases, and with synchronous metastases, respectively ( $P=0.253$; Figure $1 \mathrm{~B})$. There was no significant difference in the LRFS between patients without metastases and those with a history of metastases $(P=0.116)$, without metastases vs. synchronous metastases $(P=0.437)$, or a history of metastases vs. synchronous metastases $(P=0.550)$.

\section{Distant recurrence}

The 3-year MFS rate in all patients was 45\% (median 25.6 months), and $52 \%, 33 \%$, and $13 \%$ in patients without metastases, with a history of metastases, and with synchronous metastases, respectively $(P<0.001$; Figure 1C). Subgroup comparisons showed no significant difference between patients without metastases and those with a history of metastases ( $P=0.087$ ). Significant differences existed between patients without metastases and those with synchronous metastases $(P<0.001)$ and those with a history of metastases vs. those with synchronous metastases $(P=0.003)$.

\section{Univariable and multivariable analyses}

The results of univariable and multivariable analyses are shown in Table 4. After multivariable analysis, older age (hazard ratio [HR] 1.62; 95\% Cl 1.23-2.14; $P=0.001$ ), positive lymph nodes with the primary resection (HR 1.38; 95\% $\mathrm{Cl} 1.02-1.89 ; P=0.040$ ) and a resection with involved margins ( $\mathrm{R} 1 / 2$ resection) (HR 2.06; $95 \% \mathrm{Cl}$ $1.55-2.74 ; P<0.001)$ were associated with a worse OS, whereas neoadjuvant treatment with full-course (chemo)radiotherapy (HR 0.42; 
Metastasis-free survival

\begin{tabular}{|c|c|c|c|c|c|c|c|c|c|}
\hline$P$ value & HR & $95 \% \mathrm{Cl}$ & $P$ value & HR & $95 \% \mathrm{Cl}$ & $P$ value & HR & $95 \% \mathrm{Cl}$ & $P$ value \\
\hline & & & & 1.00 & - & & & & \\
\hline \multirow[t]{2}{*}{0.477} & & & & 1.11 & $0.74-1.68$ & 0.609 & & & \\
\hline & & & & 1.00 & - & & 1.00 & - & \\
\hline 0.450 & & & & 3.28 & $2.19-4.91$ & $<0.001$ & 3.25 & $2.11-5.02$ & $<0.001$ \\
\hline & & & & 1.00 & - & & & & \\
\hline 0.700 & & & & 1.32 & $0.77-2.26$ & 0.315 & & & \\
\hline
\end{tabular}

95\% Cl 0.21-0.81; $P=0.010$ ) and (chemo)reirradiation (HR 0.50; $95 \% \mathrm{Cl} 0.30-0.84 ; P=0.009$ ) were associated with an improved OS.

In LRFS, positive lymph nodes with the primary resection (HR 1.43; 95\% $\mathrm{Cl} 1.01-2.01 ; P=0.044)$ and an $\mathrm{R} 1 / 2$ resection (HR 3.98; $95 \% \mathrm{Cl}$ 2.83-5.59; $P<0.001$ ) were associated with a worse LRFS, whereas neoadjuvant treatment with full-course (chemo)radiotherapy (HR 0.34; 95\% Cl 0.16-0.88; $P=0.014$ ) and (chemo)reirradiation (HR 0.52; 95\% Cl 0.29-0.91; $P=0.024$ ) were associated with an improved LRFS.

The MFS was negatively associated with a positive lymph node stage of the primary tumour (HR 1.76; 95\% Cl 1.27-2.45; $P=0.001$ ) and an R1/2 resection (HR 2.25; 95\% Cl 1.64-3.09; $P<0.001$ ), whereas neoadjuvant treatment with (chemo)reirradiation positively influenced the MFS (HR 0.50; 95\% Cl 0.29-0.86; $P=0.013$ ). Moreover, patients with synchronous metastases had a worse MFS (HR 3.25; 95\% Cl 2.11-5.02; $P<0.001$ ).

\section{DISCUSSION}

This study, performed in a large cohort of 349 surgically treated LRRC patients, evaluated whether the oncological outcomes in highly selected LRRC patients with a history of metastases or with synchronous metastases were comparable to the oncological outcomes in LRRC patients without metastases. We observed an inferior MFS in patients with a history of metastases or synchronous metastases compared with patients without metastases, with a trend towards a worse OS in patients with synchronous metastases.

The 3-year MFS was worse in patients with a history of metastases (33\%) than in patients without metastases (52\%), although this difference was not statistically significant. Nonetheless, the clinical impact of this inferior MFS is high, as newly developed metastases potentially require (invasive) treatment. Despite the poor MFS, patients with a history of metastases showed a 3-year OS comparable to that in patients without metastases. The lack of impact of the inferior MFS on OS possibly indicates a relatively favourable tumour biology in patients with a history of curatively treated metastases, as the previous distant metastases were curatively treatable and allowed a sufficiently long disease-free interval to develop an LRRC that was considered feasible for curative treatment. It is reasonable to assume that distant metastases developing during post-treatment follow-up of $\mathrm{m}$-LRRC have a similar favourable tumour biology.

The 3-year MFS in patients with synchronous metastases (13\%) was significantly worse compared to patients without synchronous metastases. In contrast to patients with a history of metastases, this poor MFS tended to result in a poor OS compared to patients without metastases, suggesting aggressive tumour behaviour. As patients with LRRC and synchronous metastases were historically considered incurable and usually offered palliative treatment, there is limited scope for comparisons with the literature. Some institutions have reported findings from (sub)groups of LRRC patients with synchronous metastases who underwent intentionally curative treatment. Hagemans et al. recently reported on 193 surgically treated LRRC patients of whom $12 \%$ had treatable synchronous metastases, and observed a 3-year OS of $65 \%$, which is slightly superior to that in our study [12]. Kishan et al. observed a more similar 3-year OS rate to our study (51.6\%) in their retrospective review of 25 patients, wherein $40 \%$ of patients had synchronous metastases [15]. Kishan et al. also found that the presence of synchronous distant metastases was not associated with OS, which was also reported by 
Schurr et al. in a study on 38 patients with synchronous metastases, and is in line with the present study $[15,16]$. However, the relatively small patient population in these studies could have resulted in less statistical power. A few small studies reported on the survival in patients with synchronous metastases specifically, presenting similar median OS rates compared with our study $[17,18]$. Previous work by our group showed a median OS of 27 months in LRRC patients with synchronous metastases [9]. In this previous study, all patients were treated with induction chemotherapy, which may explain the favourable OS. However, all of the above mentioned studies, including the current study, reported on a selected group of patients, hindering direct interstudy comparison. In particular, most studies did not report on patients who began curative neoadjuvant treatment but did not undergo surgery due to progressive disease, resulting in a highly selected group of patients with a relatively favourable prognosis.

In LRRC, local control is imperative in securing quality of life as it relieves patients from tumour-related debilitating symptoms [19]. If an RO resection is achievable, extensive surgical intervention should therefore be considered. However, in the presence of synchronous metastases caution is warranted, as synchronous metastases are associated with a short MFS. This should be counterbalanced against the morbidity of neoadjuvant treatment and surgery. Thus, patient selection is of paramount importance in the presence of synchronous metastases. A possible strategy to ensure a better patient selection might include a prolonged observation of tumour behaviour, in an extended neoadjuvant treatment course comprising induction chemotherapy and chemoradiotherapy. Patients who respond well to the treatment are more likely to benefit from locoregional treatments, whereas extensive surgery may be omitted in patients with rapid progression. This staged approach is comparable to the 'liver-first' approach in patients with primary rectal cancer and synchronous liver metastases, wherein resection of liver metastases precedes resection of the primary tumour, thus precluding interruption by possible complications of the latter. A concurrent advantage of this approach is that neoadjuvant chemotherapy is used to treat and observe the response of liver metastases and primary tumour. Since tumour progression of liver metastases under neoadjuvant chemotherapy is associated with poor outcomes, in these patients extensive surgery for the rectal tumour could be avoided [20-22].

The retrospective study design confers apparent limitations, although the prospectively maintained database ensured only few missing values ( $\leq 6.3 \%$ in Table 1 and $\leq 0.9 \%$ in Table 2 ). Another limitation of the study is that it selected only patients who underwent surgery for the LRRC, excluding patients in whom surgery was omitted due to local or systemic progression during neoadjuvant therapy. Consequently, this study presents a highly selected group. Furthermore, in the group of patients with synchronous metastases a minority also had a history of metastases, who had a worse MFS than patients with synchronous metastases. However, due to low patient numbers, these groups were not analysed separately. During this study period, the treatment regimen was changed in $\mathbf{2 0 1 0}$ with the addition of induction chemotherapy, which was administered significantly more frequently in patients with synchronous metastases. Again, no subgroup analysis was performed due to the low number of patients with a history of metastases or synchronous metastases before 2010 .

The strength of this study is that the study population comprises a true sample of surgically treated patients at a large tertiary referral centre, which provides insight into the outcomes of a curative treatment approach that might greatly benefit a highly selected group of patients.

In conclusion, curative treatment of LRRC in patients with a history of metastases is possible in selected patients. Whether curative treatment should be offered to LRRC patients with synchronous metastases is questionable. Using a tailored approach, wherein the response to treatment and the natural behaviour of the disease can be observed for a prolonged duration, may enable selection of those patients who are likely to benefit from locoregional treatment of metastases and LRRC, while sparing others extensive surgery and the associated morbidity.

\section{ETHICS STATEMENT}

This study was approved by the local medical ethics board (registration number W19.031).

\section{PATIENT CONSENT STATEMENT}

No formal patient consent was required for this study, as it was a retrospective study using available data. This was confirmed by the local medical ethics board.

\section{CONFLICT OF INTERESTS}

The authors declare that they have no conflicts of interest.

\section{AUTHOR CONTRIBUTIONS}

E. L. K. Voogt and D. M. G. I. van Zoggel: Conceptualization, methodology, investigation, formal analysis, writing original draft, writing - review \& editing. M.Kusters: Conceptualization, writing - review \& editing. G. A. P. Nieuwenhuijzen: Resources, writing - review \& editing. J. S. Cnossen, G. J. Creemers, G.van Lijnschoten, J.Nederend, and M. J. Roef: Writing - review \& editing. J. W. A. Burger and H.J.T. Rutten: Conceptualization, methodology, resources, writing - review \& editing, supervision.

\section{DATA AVAILABILITY STATEMENT}

Data available from the authors upon reasonable request.

\section{REFERENCES}

1. Van Cutsem E, Cervantes A, Adam R, Sobrero A, Van Krieken $\mathrm{JH}$, Aderka D, et al. ESMO consensus guidelines for the management of patients with metastatic colorectal cancer. Ann Oncol. 2016;27(8):1386-422

2. Van Dijk TH, Tamas K, Beukema JC, Beets GL, Gelderblom AJ, de Jong KP, et al. Evaluation of short-course radiotherapy followed by neoadjuvant bevacizumab, capecitabine, and oxaliplatin and subsequent radical surgical treatment in primary stage IV rectal cancer. Ann Oncol. 2013;24(7):1762-9.

3. Kok EN, Havenga K, Tanis PJ, de Wilt JHW, Hagendoorn J, Peters $\mathrm{FP}$, et al. Multicentre study of short-course radiotherapy, systemic 
therapy and resection/ablation for stage IV rectal cancer. Br J Surg. 2020;107(5):537-45.

4. Dresen RC, Gosens MJ, Martijn H, Nieuwenhuijzen GA, Creemers GJ, Daniels-Gooszen AW, et al. Radical resection after IORTcontaining multimodality treatment is the most important determinant for outcome in patients treated for locally recurrent rectal cancer. Ann Surg Oncol. 2008;15(7):1937-47.

5. Alberda WJ, Verhoef C, Schipper MEI, Nuyttens JJ, Rothbarth J, De Wilt JHW, et al. The importance of a minimal tumor-free resection margin in locally recurrent rectal cancer. Dis Colon Rectum. 2015;58(7):677-85.

6. Bosman SJ, Holman FA, Nieuwenhuijzen GAP, Martijn H, Creemers GJ, Rutten HJT. Feasibility of reirradiation in the treatment of locally recurrent rectal cancer. Br J Surg. 2014;101(10):1280-9.

7. Nielsen MB, Laurberg S, Holm T. Current management of locally recurrent rectal cancer. Colorectal Dis. 2011;13(7):732-42.

8. van Zoggel DMGI, Bosman SJ, Kusters M, Nieuwenhuijzen GAP, Cnossen JS, Creemers GJ, et al. Preliminary results of a cohort study of induction chemotherapy-based treatment for locally recurrent rectal cancer. Br J Surg. 2018;105 4:447-52.

9. Voogt ELK, van Zoggel DMGI, Kusters M, Nieuwenhuijzen GAP, Bloemen JG, Peulen HMU, et al. Improved outcomes for responders after treatment with induction chemotherapy and chemo(re)irradiation for locally recurrent rectal cancer. Ann Surg Oncol. 2020;27(9):350313. https://doi.org/10.1245/s10434-020-08362-4

10. van den Brink $M$, Stiggelbout AM, van den Hout WB, Kievit J, Klein Kranenbarg E, Marijnen CAM, et al. Clinical nature and prognosis of locally recurrent rectal cancer after total mesorectal excision with or without preoperative radiotherapy. J Clin Oncol. 2004;22(19):3958-64.

11. Detering R, Karthaus EG, Borstlap WAA, Marijnen CAM, van de Velde $\mathrm{CJH}$, Bemelman WA, et al. Treatment and survival of locally recurrent rectal cancer: a cross-sectional population study 15 years after the Dutch TME trial. Eur J Surg Oncol. 2019;45(11): 2059-69.

12. Hagemans JAW, van Rees JM, Alberda WJ, Rothbarth J, Nuyttens JJME, van Meerten E, et al. Locally recurrent rectal cancer; longterm outcome of curative surgical and non-surgical treatment of 447 consecutive patients in a tertiary referral centre. Eur J Surg Oncol. 2020;46(3):448-54.

13. Martin TA, Ye L, Sanders AJ, Lane J, Jiang WG. Cancer invasion and metastasis: molecular and cellular perspective. In: Madame Curie Bioscience Database. Austin (TX): Landes Bioscience; 2000-2013. https://www.ncbi.nlm.nih.gov/books/NBK164700/

14. Leong L. Clinical relevance of targeting cancer metastases. In: Madame Curie Bioscience Database. Austin (TX): Landes Bioscience; 2013. p. 8-10. https://www.ncbi.nlm.nih.gov/books/NBK154382/
15. Kishan AU, Voog JC, Wiseman J, Cook RR, Ancukiewicz M, Lee P, et al. Standard fractionation external beam radiotherapy with and without intraoperative radiotherapy for locally recurrent rectal cancer: the role of local therapy in patients with a high competing risk of death from distant disease. Br J Radiol. 2017;90(1076):20170134.

16. Schurr P, Lentz E, Block S, Kaifi J, Kleinhans H, Cataldegirmen G, et al. Radical redo surgery for local rectal cancer recurrence improves overall survival: a single center experience. J Gastrointest Surg. 2008;12:1232-8.

17. Cyr DP, Zih FS, Wells BJ, Swett-Cosentino J, Burkes RL, Brierley JD, et al. Long-term outcomes following salvage surgery for locally recurrent rectal cancer: a 15-year follow-up study. Eur J Surg Oncol. 2020;46(6):1131-7.

18. Hartley JE, Lopez RA, Paty PB, Wong WD, Cohen AM, Guillem JG. Resection of locally recurrent colorectal cancer in the presence of distant metastases: can it be justified? Ann Surg Oncol. 2003;10:227-33.

19. You YN, Habiba H, Chang GJ, Rodriguez-Bigas MA, Skibber JM. Prognostic value of quality of life and pain in patients with locally recurrent rectal cancer. Ann Surg Oncol. 2011;18(4):989-96. https://doi.org/10.1245/s10434-010-1218-6

20. Verhoef C, Van Der Pool AEM, Nuyttens JJ, Planting AST, Eggermont AMM, De Wilt JHW. The "liver-first approach" for patients with locally advanced rectal cancer and synchronous liver metastases. Dis Colon Rectum. 2009;52(1):23-30.

21. Ayez N, Burger JWA, Van Der Pool AE, Eggermont AMM, Grunhagen DJ, De Wilt JHW, et al. Long-term results of the "liver first" approach in patients with locally advanced rectal cancer and synchronous liver metastases. Dis Colon Rectum. 2013;56(3):281-7.

22. Adam R, Pascal G, Castaing D, Azoulay D, Delvart V, Paule B, et al. Tumor progression while on chemotherapy. Ann Surg. 2004;240(6):1052-64.

\section{SUPPORTING INFORMATION}

Additional supporting information may be found online in the Supporting Information section.

How to cite this article: Voogt EL, Zoggel DM, Kusters M, et al. Impact of a history of metastases or synchronous metastases on survival in patients with locally recurrent rectal cancer. Colorectal Dis. 2021;23:1120-1131. https://doi. org/10.1111/codi.15537 